\title{
VIRTUALISING THE QUANTITATIVE RESEARCH METHODS COURSE: AN ISLAND-BASED APPROACH
}

\author{
JAMES BAGLIN \\ School of Mathematical and Geospatial Sciences, RMIT University \\ james.baglin@rmit.edu.au \\ JOHN REECE \\ Discipline of Psychology, School of Health Sciences, RMIT University \\ john.reece@rmit.edu.au \\ JENALLE BAKER \\ School of Mathematical and Geospatial Sciences, RMIT University \\ jenalle.baker@rmit.edu.au
}

\begin{abstract}
Many recent improvements in pedagogical practice have been enabled by the rapid development of innovative technologies, particularly for teaching quantitative research methods and statistics. This study describes the design, implementation, and evaluation of a series of specialised computer laboratory sessions. The sessions combined the use of an online virtual world, cloud collaboration technology, and a statistical package in order to simulate the entire data investigative cycle. The sessions covered multiple topics, research designs, and data analysis techniques relevant to psychology. Quantitative and qualitative feedback data regarding students' perceptions of the sessions were analysed. The results demonstrate promising support for the use of Island-based sessions, but improvements and further research will be required.
\end{abstract}

Keywords: Statistics education research; Virtual worlds; Educational technology; Cloud collaboration; Statistical package; Statistical thinking

\section{INTRODUCTION}

The goal of all research is to improve understanding and create new knowledge. Research methods, whether they are qualitative, quantitative, or mixed, refer to the specific processes used to advance understanding. The sciences are dominated largely by quantitative methods - that is, mathematical or statistical - which assume that knowledge can be gained through measurement. As methods of measurement and data collection will lead to variations in the statistical models used (Snee, 1990), some instructors argue there is no practical distinction between quantitative research methods and statistics (Saville, 2008). Therefore, many statistics instructors advocate a more holistic conception of statistical practice to acknowledge the inherent link to research methodology (Holmes, 1997; MacGillivray \& Pereira-Mendoza, 2011; Marriott, Davies, \& Gibson, 2009). In the broadest sense, quantitative research methods are problem-solving tools, where the problem is usually in the form of a research question or hypothesis. To capture the important elements of statistical problem solving, MacKay and Oldford (1994) proposed the Problem, Plan, Data, Analysis, and Conclusions (PPDAC) data investigative cycle.

Statistics Education Research Journal, 14(2), 28-52, http://iase-web.org/Publications.php?p=SERJ (C) International Association for Statistical Education (IASE/ISI), November, 2015 
Similarly, Marriott et al. (2009) use Problem, Collect Data, Process, and Discuss (PCPD). All methods of quantitative research span the data investigative cycle, connecting hypotheses, data, analysis, and conclusions, but are defined by different methods of data collection and research design, including: questionnaires, designed experiments, and observational or correlational studies. The data investigative cycle inherent in quantitative research methods underpins modern conceptions of statistical thinking (Pfannkuch \& Wild, 2000, 2005; Wild \& Pfannkuch, 1999); hence, quantitative research methods courses must serve to develop statistical thinking in its broadest sense.

Knowledge of the data investigative cycle is required by all students planning to engage in independent research (Ball \& Pelco, 2006). This knowledge can also benefit students who must make informed decisions in everyday and professional roles (Zablotsky, 2001). Regardless of these advantages, students have reported poor attitudes towards quantitative research methods courses, finding them to be uninteresting, irrelevant, and anxiety provoking (Briggs, Brown, Gardner, \& Davidson, 2009; Gladys, Nicholas, \& Crispen, 2012; Meldrum \& Stults, 2012). Furthermore, Meldrum and Stults (2012) found that poor student attitudes measured at the beginning of a research methods course were related to negative course performance. Indeed, meta-analytic work in statistics education has confirmed the presence of this attitude-achievement relationship across 17 individual studies (Emmioğlu \& Yesim, 2012). The attitude-achievement relationship is important because, as Ramirez, Schau and Emmioğlu (2012) argue using their Model of Students Attitudes Toward Statistics, attitudes determine student effort and engagement in learning statistics, and later employment of these skills. Unfortunately, these attitudes appear resistant to change. Sizemore and Lewandowski (2009) found over the semester of a research methods course in psychology, students' attitudes towards research methods either remained unchanged or significantly degraded despite students' knowledge increasing. Together, these findings highlight the importance of enhancing the student experience of quantitative research methods courses in order to improve knowledge along with attitudes.

Pedagogical approaches used in research methods courses have been studied extensively. Active learning approaches, which view the student as an active participant in the learning process (Bell \& Kozlowski, 2008), have been used with reported success (Ball \& Pelco, 2006; Barraket, 2005; Benson \& Blackman, 2003; Crull \& Collins, 2004; Winn, 1995). Examples of active learning methods include research projects, group discussions, and tutorial exercises. MacGillivray and Pereira-Mendoza (2011) strongly advocated project-based work because it develops statistical thinking and knowledge of quantitative research methods by experientially engaging students in all aspects of the data investigative cycle, creating an authentic learning experience (Forster \& MacGillivray, 2010; Longmore, Dunn, \& Jarboe, 1996; Snee, 1993). However, major practical and ethical constraints have limited the degree to which students are able to meaningfully engage in research as it is practiced (Bulmer \& Halaydn, 2011; Nelson \& Ketelhut, 2007; Winn, 1995). Addressing the pedagogical needs of quantitative research methods students creates a substantial challenge, requiring innovative solutions. One idea has been to simulate a quantitative research experience using educational technology.

Educational technology has provided instructors with new approaches to help improve the delivery of quantitative research methods courses. Many technologies exist that can enable the data investigative cycle to be simulated. So-called "synthetic learning environments" (Cannon-Bowers \& Bowers, 2010, p. 229), for example, games, simulations, and virtual environments, have been used extensively for educational purposes (e.g., Dobson, 2009; Lemmon, Lui, Cottrell, \& Hamilton, 2012; Lin \& Lehman, 1999; Neumann, Neumann, \& Hood, 2011; Spinello \& Fischbach, 2004; Stafford, Goodenough, \& Davies, 2010), and are well positioned to bridge the theory-practice gap. Such 
simulations assume that learning is most likely to occur in meaningful and applicable contexts through the transformation of experience - that is, experiential learning (Kolb, 1984; Kolb, Boyatzis, \& Mainemelis, 2001). Experiential learning is inherently active. Virtual simulations also bypass many practical and ethical barriers (Stafford et al., 2010), while allowing high levels of authenticity and engagement, and providing a rich context (Cannon-Bowers \& Bowers, 2010; Galvao, Martins, \& Gomes, 2000). Other technologies used to meet practical classroom constraints include cloud collaboration and statistical packages for streamlined data collection and analysis. In the following sections, each technology will be outlined as it pertains to virtualising the data investigative cycle.

\subsection{THE ISLAND}

Bulmer and Haladyn (2011) describe the development of a free, online human population simulation known as the Island (http://island.maths.uq.edu.au) and more recently, a new version referred to as the Islands (https://islands.smp.uq.edu.au). The original Island used during this study consisted of 39 villages and was home to approximately 9000 virtual Islanders. The Island was created by a simulation fastforwarded from an initial seeding population of 108 shipwrecked survivors some 240 years ago. The simulation aimed to develop a stable population with realistic disease, birth, death, marriage, and relocation trends. Once created, the Island simulation was slowed to run in real time. Every month, the Island updates statistical models governing births, deaths, relationships, and health. A rich source of historical data is captured by the Island's village halls located in the central hamlets of each village (see Figure 1a). Houses within each hamlet are occupied by Islanders (see Figure 1b). The conceptual and spatial design of the Island allows students to experience the challenge of implementing proper sampling methods (see Figure 2).

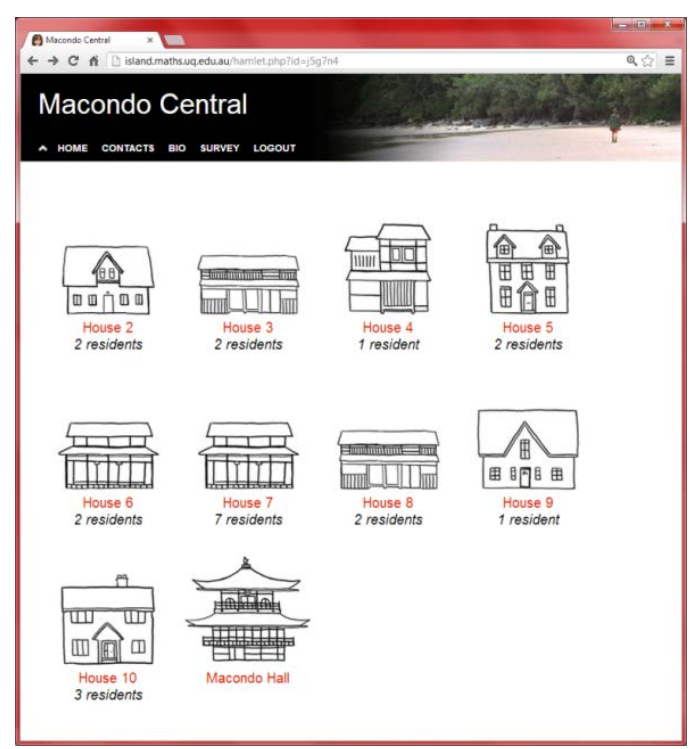

(a)

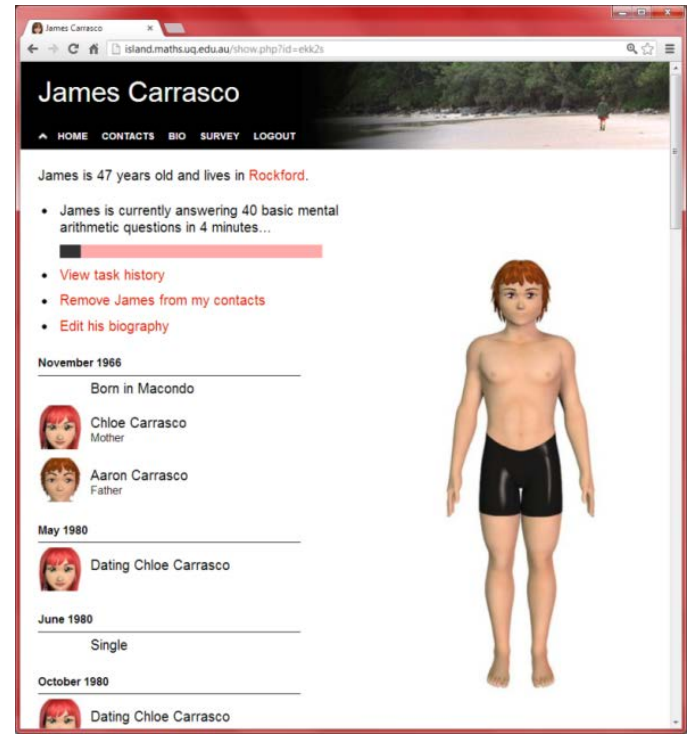

(b)

Figure 1. a) The Island hamlet of Macondo Central showing the village hall. b) An Islander completing a mental arithmetic task.

The Island also includes many other simulation models (see Figure $1 \mathrm{~b}$ ) governing the Islanders' responses to various tasks that can be allocated after obtaining their ethical 
consent. These models randomly generate realistic responses to task interactions and log the islanders' activities and results in their history. For example, having an Islander consume alcohol (e.g., Vodka $30 \mathrm{ml}$ ) will impact their performance on cognitive tasks (e.g., Memory Game). These simulations run almost in real time (30-second intervals) meaning students need to wait for activities to complete or the effects of drugs and other substances to set in. The simulation models are, as much as possible, based on the results of real research (see Bulmer \& Haladyn, 2011). The wide range of (approximately 200) tasks available makes for a relatively open-ended research experience, meaning the Island can cater to a wide range of topics and audiences. Examples of tasks include surveys, blood tests, urine tests, physiological measurements, alcoholic drinks, non-alcoholic drinks, food, injections, tablets, other drugs (e.g., Betel nut), mental tasks, coordination, exercise, music, environmental (e.g., Swedish massage), and miscellaneous (e.g., chewing gum).

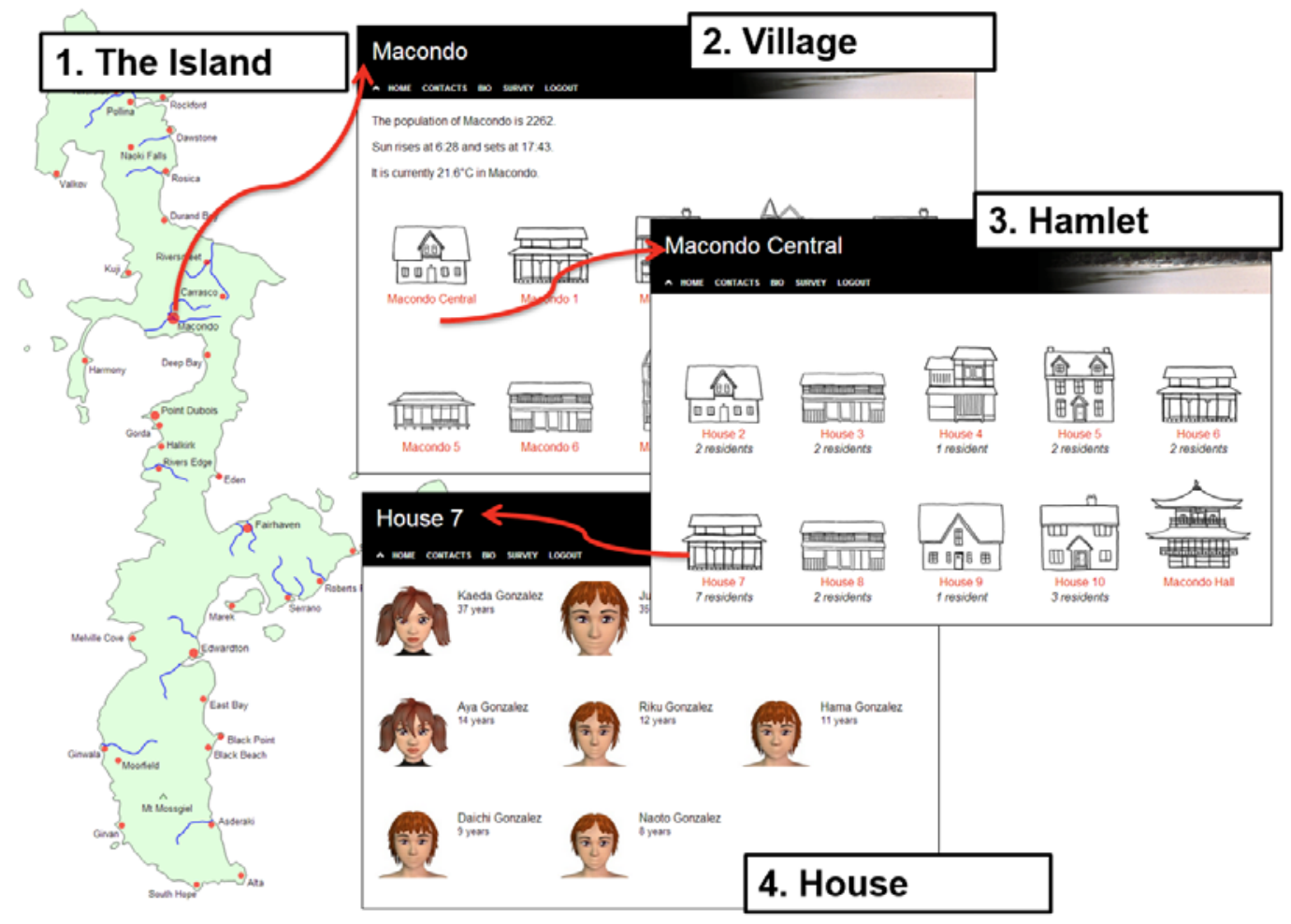

Figure 2. A breakdown of the Island.

The original conception of the Island was as a realistic research experience for projectbased learning in large introductory statistics courses (Bulmer, 2010). As such, students will experience the difficult nature of sampling from a population, time constraints, participants declining consent, drop-outs (e.g., death), lying on surveys, participants getting sick, and falling asleep at night. Each Islander has a unique personal history and genetic make-up that adds to the realism. Students discover that islanders inherit traits from their parents and report feeling empathy for islanders with tragic lives. The Island allows a range of research designs to be implemented. Examples of possible designs include experiments, survey studies, retrospective case-control studies, and observational studies. Longitudinal studies are possible, but are typically impractical because of the real time nature of the Island. 


\subsection{CLOUD COLLABORATION}

Cloud collaboration refers to a method of co-authoring documents and files via centralised “cloud”-based storage (Wikipedia, n.d.). Cloud collaboration technologies have a potential to transform teaching and learning practices profoundly (Nevin, 2009; Thomas, 2011). Google Apps, a set of web applications Google offers as an online alternative to traditional office suites of interrelated desktop applications, has particularly powerful collaboration features that allow real-time, simultaneous editing of word documents and spreadsheets. Using this technology in a quantitative research methods class can allow students to input data into a centralised class spreadsheet. Large datasets can be created by using a class to crowdsource data collection. Google Apps run virtually on any platform (Windows, Mac, Linux, and Android), provided an internet connection is present. At the time of the study, the Google Apps documentation cited a limit of 50 users for simultaneous editing.

\subsection{STATISTICAL PACKAGES}

A statistical package is software designed for the specific purpose of manipulating, analysing, and presenting data (Chance, Ben-Zvi, Garfield, \& Medina, 2007). A common example is IBM SPSS Statistics (IBM Corp., 2013), henceforth referred to as SPSS. Statistical packages are the most common form of technology used in the teaching of quantitative research methods and statistics courses. Statistical packages have major advantages for instructors, including: automating complex statistical formulae, demonstrating difficult concepts (Smith, 2003), and familiarising students with common research software (Oswald, 1996). Using statistical packages allows students to spend more time exploring and analysing data and less time working with calculations that are better left to the technology. The ability to use a statistical package is an important quantitative research skill that will help students engage meaningfully in modern statistical practice (Gould, 2010).

\subsection{RATIONALE AND AIM}

The Island has been successfully utilised in a range of courses for project-based learning, including clinical trial design and management (Linden, Baglin, \& Bedford, 2011), introductory statistics (Bulmer, 2010), and biostatistics (Baglin, Bedford, \& Bulmer, 2013). Preliminary work was completed by Baglin, Reece, Bulmer, and Di Benedetto (2013) using the Island to develop specialised computer laboratory sessions for simulating the data investigative cycle in a psychology research methods course. These sessions required students to work through the PPDAC cycle within a two-hour computer laboratory session using the Island, Google Spreadsheets for collaborative class data collection, and a statistical package for data analysis. Research topics changed each week to expose students to different types of research designs, which included surveys, quasi-experiments, randomized experiments, correlational studies, and observational studies. Pilot feedback from 33 students was overwhelmingly positive with $94 \%$ of students agreeing the computer laboratory sessions were a positive experience. The students found the sessions to be interactive, practical, and relevant. However, some students felt the technology skills required were overwhelming and that perhaps too much was being covered in each session. These pilot results were promising, but almost all students enrolled in the course had previously completed an introductory statistics course. Their knowledge of statistics may have reduced the cognitive burden of the sessions and inflated their positive perceptions. 
Students without a statistics background may have a different experience. The researchers concluded that further student evaluation in more diverse cohorts was needed.

The aim of this study was to detail the design, implementation, and student evaluation of a series of Island-based computer laboratory sessions used in a large psychology research methods course. Due to the reported issues with student engagement in quantitative research methods courses, the primary evaluation focused on students' attitudes towards the sessions and factors that impacted their experience. This was important to understand from a research perspective because positive student attitudes and acceptance of the novel computer laboratory sessions were important outcomes to achieve, and gathering student evaluation data would assist in future development. Also, understanding the factors likely to impact the student experience may help in planning an effective implementation in other courses. Building upon the findings of Baglin et al. (2013), this study implemented the specialised Island-based laboratory sessions in a larger and more diverse student cohort. To summarise, the study had the following research questions:

1. How can an online virtual world, cloud collaboration technology, and a statistical package be used in order to simulate the entire data investigative cycle in regular two-hour psychology research methods courses?

2. Do students agree that the Island-based computer laboratories meet their learning needs in terms of engagement, level of difficulty, and relevancy?

3. Does students' prior statistical knowledge, discipline background, computer lab environment, tutor, or course performance impact their experience of the Island-based computer laboratory sessions?

4. What do students self-report enjoying the most about the Island-based computer laboratory sessions and what elements do they believe are in need of improvement?

\section{SESSION DESIGN}

\subsection{THE COURSE}

The study took place in a cross-campus, undergraduate and postgraduate research methods course in psychology. Students enrolled in the course were mainly second-year undergraduate psychology students. The three main psychology programs included applied psychology, social science, and a social science and social work double degree. Honours and postgraduate students in other health sciences disciplines could also enroll. The objective of the course was to introduce the main research methodologies and data analysis techniques used in psychological research. The outcomes of the course included the ability to apply different research designs, critically evaluate published research, and interpret and apply fundamental data analysis methods. Table 1 outlines the course topics covered across the semester. The weekly course contact hours across the 12-week semester included a twohour lecture and a two-hour tutorial (weeks 1-3) or computer laboratory session (week 4 onwards). Computer laboratory sessions are referred to as 'labs' in this paper. Assessment involved an end of semester multiple-choice comprehensive exam (40\%), a methodology and data analysis assignment (30\%), a lab report (20\%), and lab participation (10\%).

Prior to this study, the labs required students to complete worksheets relating to the statistical analysis of pre-existing psychology datasets. The sessions were largely selfdirected, but with tutors on hand for assistance. The specialised Island-based labs began in week 4 and covered two-hour blocks. Because the course was spread across two campuses, the lecture was delivered live on campus A, recorded using screen casting technology, and 
then made available online for viewing at campus B. Weekly tutorials and labs were run by five different course tutors across both campuses. All tutors were trained by the lead researcher for one hour prior to the labs commencing in week 4 and were provided with the lab worksheets prior to each session to go through in their own time. Pre-lab tutor briefing sessions were also scheduled an hour before class. During these information sessions, the lead researcher outlined the lab content and provided a forum for tutors to ask questions and discuss any challenges. There were nine different lab classes, most running back-to-back on campus A, which had the majority of enrollments. Lab class sizes ranged from 20-30 students.

\subsection{DESIGNING THE ISLAND-BASED COMPUTER LABS}

Eight Island-based labs covering seven psychology-related research topics were implemented across the semester (see Table 1). Each lab topic was lagged one week behind the related lecture content. The aim of each lab was to engage students actively in the entire PPDAC data investigative cycle and to do so in an authentic and practical way. To achieve this goal, the sessions would simulate each stage within the two-hour labs using the Island, cloud collaboration, and a statistical package. However, due to limited lab time, briefings were provided to students prior to attending each session. The briefings aimed to cover the problem and planning stages. This saved considerable lab time and ensured all classes had the same instructions before commencing. The briefing sessions introduced the research topic and explained the research design and data collection method that would be undertaken by each class. Hints and tips for data analysis were also incorporated to assist students in using some of the more difficult procedures of the statistical package. The briefings were delivered and recorded on campus $B$ and made accessible online to students prior to their labs on campus A. The early briefing sessions during the Psychological Health Survey topic (see Table 1) focused mainly on explaining sampling from the Island population.

The Island sampler was a downloadable spreadsheet that assisted students in randomly sampling participants given that there was little time to have students devise their own method. The random sampling spreadsheet allowed students to implement probabilistic sampling methods on the Island and gain a conceptual understanding of the mechanics behind the tool. The sampling method behind the sampler, a two-stage clustered random sampling method, first randomly selected an Island village, weighted by the hamlet's population size, and then randomly selected a hamlet within the village. The tool then assisted students in randomly selecting $n$ Islanders from the hamlet using a simple random sampling technique. This required students to record the population size, $N$, of the hamlet. The students then randomly generated numbers between 1 and $N$ using the sampler tool to select a desired number of participants (see Figure 3). Each lab class acted as a research team for data collection. Each student was tasked with recruiting a small number - from 3 to 10 - of randomly-selected Islanders which would be combined into a large class data sheet using Google Spreadsheets. Google's cloud collaboration technology allowed up to 50 students within a class to enter data simultaneously from their random samples. Combining the small number of random samples from each student enabled each lab class to gather a large random sample in a short period of time and have the entire data set available to the class for download and analysis. 
Table 1. Course Schedule and Island-based Labs

\begin{tabular}{|c|c|c|c|}
\hline Week & Course Topic & Island-based Session & Brief Description \\
\hline 1 & Introduction & Not applicable & Not applicable \\
\hline 2 & $\begin{array}{l}\text { Research Design and } \\
\text { Hypothesis Testing }\end{array}$ & Regular classroom tutorial I & Not applicable \\
\hline 3 & - & Regular classroom tutorial II & Not applicable \\
\hline 4 & Introduction to SPSS & 1. Pilot Study & $\begin{array}{l}\text { Introduction to using the Island, } \\
\text { Google Spreadsheets, and SPSS }\end{array}$ \\
\hline 5 & $\begin{array}{l}\text { Exploratory Data } \\
\text { Analysis }\end{array}$ & $\begin{array}{l}\text { 2.1 Psychological Health } \\
\text { Survey I }\end{array}$ & $\begin{array}{l}\text { Gather survey data from a random } \\
\text { sample of Islanders }\end{array}$ \\
\hline $6 \& 7$ & - & $\begin{array}{l}\text { 2.2. Psychological Health } \\
\text { Survey II }\end{array}$ & $\begin{array}{l}\text { Screen and clean survey data in SPSS } \\
\text { Perform exploratory data analysis in } \\
\text { SPSS }\end{array}$ \\
\hline 8 & Comparing means & $\begin{array}{l}\text { 3. Gender and Self-estimated } \\
\text { Intelligence }\end{array}$ & $\begin{array}{l}\text { Quasi-experimental study } \\
\text { demonstrating the use of a two-sample } \\
\text { t-test }\end{array}$ \\
\hline 9 & Correlation & $\begin{array}{l}\text { 4. Cannabis Use and } \\
\text { Reaction Time }\end{array}$ & $\begin{array}{l}\text { Repeated measures experiment } \\
\text { demonstrating the use of a paired- } \\
\text { samples } t \text {-test. }\end{array}$ \\
\hline 10 & $\begin{array}{l}\text { Categorical } \\
\text { Associations }\end{array}$ & $\begin{array}{l}\text { 5. Correlates of Self-rated } \\
\text { Attractiveness }\end{array}$ & $\begin{array}{l}\text { Correlational study demonstrating the } \\
\text { use of correlation. }\end{array}$ \\
\hline 11 & $\begin{array}{l}\text { Comparing many } \\
\text { means }\end{array}$ & $\begin{array}{l}\text { 6. Murder and Relationship } \\
\text { Breakups }\end{array}$ & $\begin{array}{l}\text { Case-control study demonstrating the } \\
\text { application of a chi-square test of } \\
\text { association }\end{array}$ \\
\hline 12 & Revision & $\begin{array}{l}\text { 7. Methamphetamine and } \\
\text { Attention }\end{array}$ & $\begin{array}{l}\text { True randomised experiment } \\
\text { demonstrating the use of one-way } \\
\text { analysis of variance }\end{array}$ \\
\hline
\end{tabular}

For each session, students were provided with worksheets outlining the learning outcomes, the research topic, and required tasks to complete for each session. The first session, a pilot study, was used to introduce and familiarise the students with the Island and Google Spreadsheets. There was no particular topic for this session as students were encouraged to explore the Island and gather some interesting data from a small sample of Islanders. Students were then required to practice entering the data into a personal Google Spreadsheet, exporting the data from Google and importing the file into the statistical package SPSS. The pilot session was important to deal with any technology-related issues (e.g., Island access) and build the confidence of the students and tutors prior to the full sessions. 


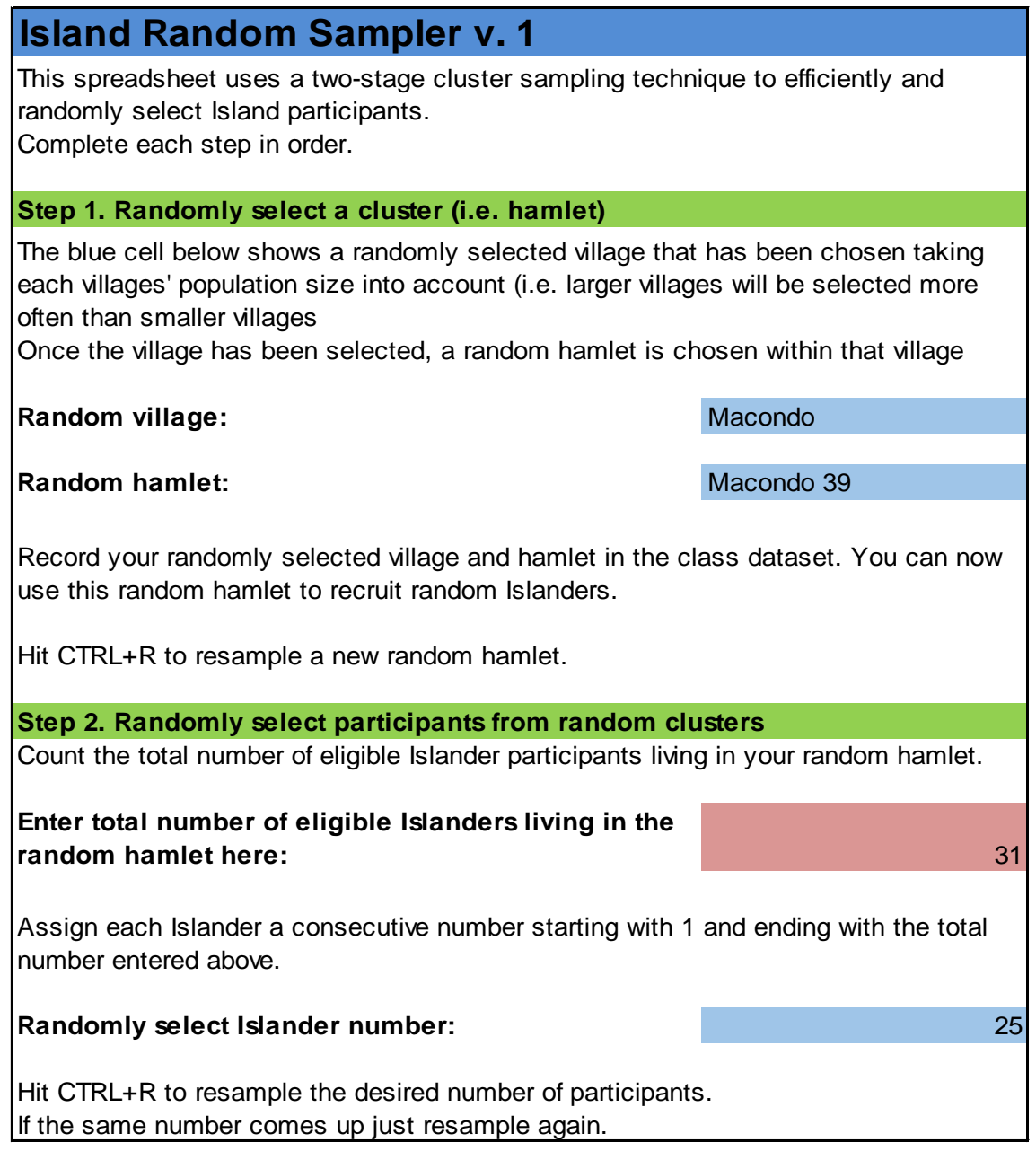

Figure 3. Island sampler used by students to randomly select participants.

The first full session, the Psychology Health Survey, was spread across three weeks while students were learning to use SPSS and conduct exploratory data analysis (descriptive statistics, graphical displays, and checking parametric assumptions). During these sessions students were required to administer an Island health survey consisting of 12 questions (e.g., “On a scale from 1 to 10, how anxious do you feel right now?”) to a large random sample of Islanders. Each student was required to randomly sample 10 Islanders for their class and have them fill in the survey. Each student then uploaded their data from their 10 Islanders into a combined class Google Spreadsheet, which was prepared prior to the class. For example, the total Psychology Health Survey sample sizes for the nine classes ranged from approximately 200 to 300 . The spreadsheet was labelled with the appropriate variable names and structured to enable easy importation into SPSS. As students were simultaneously entering large amounts of data into their class's cloud-based spreadsheet, there were many opportunities for mistakes to occur, and different ways of coding variables. The idea was to create a messy data file that students would be required to "screen and clean" in subsequent sessions. Example of messiness included data entry errors, the use of numeric codes or text for defining categories, inconsistent category coding, for example "Female” vs. "female” vs. “f” vs. "2", and missing values.

Once the class data were entered, students individually downloaded the class data and imported it into SPSS. They gained experience in carefully screening and cleaning datasets 
prior to analysis. They also learned how to fix data entry mistakes efficiently and recode variables using the built-in features of SPSS. Once they made it to exploratory data analysis, students gained experience with summarising the essential features of the data using descriptive statistics and exploring distributions of variables using graphical displays. Students applied assumption tests to continuous data and experimented with transformation techniques in order to find solutions to common problems with non-normality and heteroscedasticity. The final task during these sessions was to compare males and females numerically and graphically on mental health variables and then report these findings in a short abstract formatted according to the guidelines of the American Psychological Association (2010). This allowed students to practice discipline-specific writing styles. Students were encouraged to get feedback from tutors on their write-up prior to finishing, and this was used to record student participation.

Subsequent labs consisted of one topic per session and each shared a very similar structure. In order to overview the structure of sessions 3-7, the Cannabis Use and Reaction Time topic will be used as an example. The pre-lab briefing provided the problem context and outlined the research design and data collection method. This topic aimed to evaluate the effect of cannabis on a test of simple reaction time. The experiment was contextualised in terms of understanding the possible effect of illicit drugs on drivers' performance. The session required students to implement a simple repeated measures experiment protocol. Each student randomly selected three adult participants from the Island that would be combined into a class Google Spreadsheet. The participants had their baseline reaction time measured using a light flash test. (This test required Islanders to press a button, which records reaction time in milliseconds, as quickly as possible after a light flashes on at a random time point.) Each student then had their consenting adult Islanders smoke cannabis for ten minutes, wait five minutes for the drug to take effect and then re-measure reaction times. Each student uploaded their data to their class' Google Spreadsheet. The combined class data was individually downloaded from the Google Spreadsheet, imported into SPSS, screened and cleaned, explored, assumptions checked, and hypothesis tests conducted. The students finished by writing an individual abstract summarising findings using APA style. Figure 4 overviews how each stage of the PPDAC cycle was related to the various elements of the sessions and the technologies used.

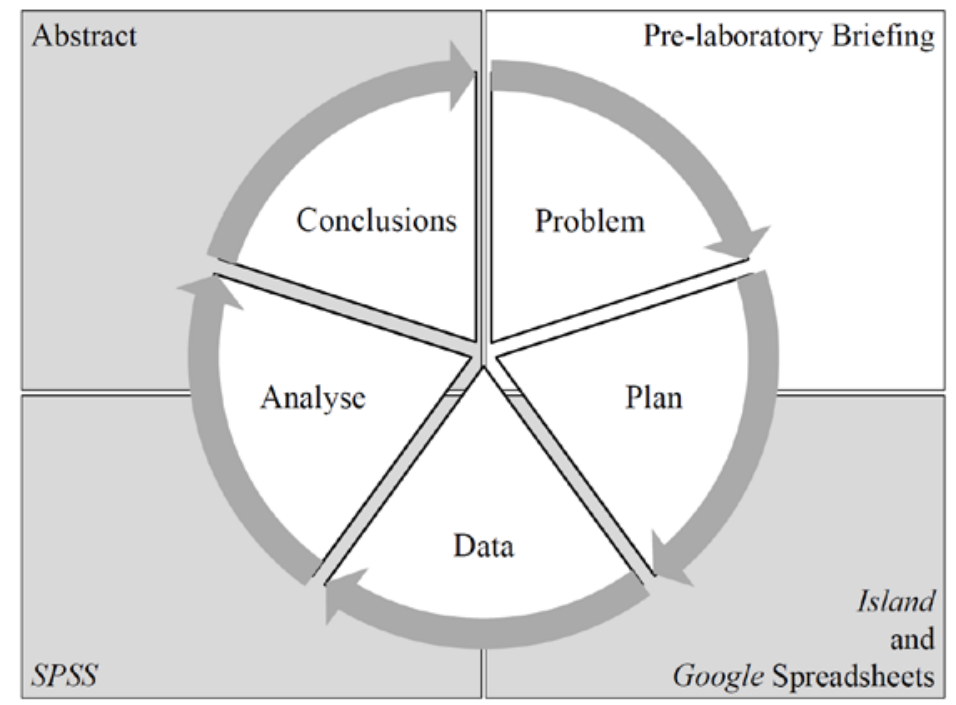

Figure 4. The PPDAC cycle and computer lab design. (grey shaded boxes denote computer lab time) 


\section{EVALUATION METHOD}

\subsection{PARTICIPANTS AND PROCEDURE}

Following institutional ethics approval, all undergraduate students in the applied psychology, social science, and social science and social work double degree programs enrolled in the psychology research methods course were approached in the final lab and given the opportunity to fill out the computer lab satisfaction questionnaire. Requests to fill out an online version of the questionnaire were emailed to students who did not attend the final lab. Students enrolling from other undergraduate $(N=6)$ and postgraduate programs $(N=9)$ were excluded due to their small representation within the course. Plain language statements and consent forms were attached to the questionnaire.

For campus A, a total of 168 students from applied psychology, social science, and social science and social work were enrolled, of which 124 (74\%) consented and provided feedback related to the Island-based labs. For campus B, there were 31 applied psychology students enrolled, of which 20 (65\%) filled out the end-of-semester questionnaire. Due to the large overlap between the social science and social science and social work double degree programs, the two programs were grouped together into the social science and social work program. Table 2 shows the distribution of important background factors between the two main program groupings. The students were predominantly female and aged 18-24 years. The major difference between the programs was related to previous statistics courses. The majority of the applied psychology students had completed an introductory statistics course and many were enrolled in a second-year intermediate statistics elective (see Table 2). This was due to the different program structures. It was possible for some applied psychology students to have no statistics background (9.2\%) due to mid-term intake cohorts who would enroll in the introductory course during their second year.

Students self-reported their attendance to the eight Island-based labs (see Table 1). Participants' final exam scores were also recorded as an indicator of student performance in the course. Exam scores were considered separately from the overall course grade because the overall grade included assessment that was marked individually by different tutors (i.e. methodology and data analysis assignment and a lab report). This would introduce dependency into the student performance indicator. The multiple-choice exam score was considered more reliable as all students completed the same exam and the exam was scored by an electronic marking machine (in contrast to the essays and lab reports, which were graded by the tutors).

\subsection{COMPUTER LABORATORY SATISFACTION INDEX}

A computer laboratory satisfaction index (CLSI) was created by adapting 18 questionnaire items from previous work by Linden et al. (2011) and Baglin et al. (2013). The items required students to rate their attitudes towards lab engagement (e.g., "I enjoyed the computer laboratory sessions in this course."), difficulty (e.g., "I found it difficult to complete the computer laboratory sessions."), and relevance (e.g., "The computer laboratory sessions helped me to understand the relationship between research design and statistical analysis.”) using a seven-point Likert-type scale ranging from 1 (strongly disagree) to 7 (strongly agree; see Appendix Table A for the complete items).

In order to explore the underlying structure of the CLSI items, data were combined from the 144 respondents and Exploratory Factor Analysis (EFA) was performed. The results of the Kaiser-Meyer-Olkin (KMO) and Bartlett's test of sphericity supported the suitability of the data for EFA. The KMO statistic was excellent at .95 and Bartlett's test 
of sphericity was statistically significant: $\chi^{2}(153)=2302.6, p<.001$. EFA was carried out using the software package FACTOR (Lorenzo-Seva \& Ferrando, 2006). The polychoric correlation matrix was analysed due to the ordinal rating of the items. Parallel analysis (PA) using minimum rank factor analysis (Shapiro \& Berge, 2002; ten Berge \& Kiers, 1991; Timmerman \& Lorenzo-Seva, 2011) was chosen as the retention and extraction method, respectively. The PA supported a unidimensional scale despite the three proposed domains (engagement, difficulty, and relevance) incorporated into the development of the scale (see Appendix Table A for factor loadings and communalities). This suggested that three satisfaction domains were highly correlated with each other and, combined together, represented a composite indicator of lab satisfaction. The total common variance explained by the unidimensional scale was 73.4\%. All items had loadings above 0.3 and communalities above 0.4 (Costello \& Osborne, 2005). Cronbach's $\alpha$ was calculated as a measure of the internal consistency among the 18 items. The two negatively-worded items were reverse-scored prior to this analysis. Cronbach's $\alpha=.96$ demonstrated acceptable internal consistency. The results of the EFA meant that the 18 items could be averaged for each respondent in order to calculate the CLSI, which represented attitudes towards the relevancy, engagement, and difficulty of the sessions. Average scores could range from 1 to 7, with higher scores indicating more positive attitudes towards the sessions. CLSI scores above 4 , where 4 referred to a neutral response on the seven-point Likert-type scale, were regarded as tending towards agreement, while scores 4 or below were regarded as tending towards no agreement.

Table 2. Sample Characteristics across Program Groupings

\begin{tabular}{|c|c|c|c|c|c|c|c|}
\hline \multirow[t]{2}{*}{ Variable } & & \multicolumn{2}{|c|}{$\begin{array}{c}\text { Applied psychology } \\
\qquad(N=87)\end{array}$} & \multicolumn{2}{|c|}{$\begin{array}{l}\text { Social science } \\
\& \text { social work } \\
(N=57)\end{array}$} & \multicolumn{2}{|c|}{$\begin{array}{l}\text { Combined } \\
(N=144)\end{array}$} \\
\hline & & $N$ & $\%$ & $N$ & $\%$ & $N$ & $\%$ \\
\hline \multirow[t]{2}{*}{ Gender } & Female & 64 & 73.6 & 42 & 73.7 & 106 & 73.6 \\
\hline & Male & 23 & 26.4 & 15 & 26.3 & 38 & 26.4 \\
\hline \multirow[t]{4}{*}{ Age } & $18-24$ & 76 & 87.4 & 43 & 75.4 & 119 & 82.6 \\
\hline & $25-34$ & 8 & 9.2 & 9 & 15.8 & 17 & 11.8 \\
\hline & $35-44$ & 3 & 3.4 & 4 & 7.0 & 7 & 4.9 \\
\hline & $45-54$ & 0 & 0.0 & 1 & 1.8 & 1 & 0.7 \\
\hline \multirow[t]{2}{*}{ Residency } & National & 84 & 96.6 & 48 & 84.2 & 132 & 91.7 \\
\hline & International & 3 & 3.4 & 9 & 15.8 & 12 & 8.3 \\
\hline \multirow[t]{2}{*}{ Load } & Part-time & 2 & 2.3 & 2 & 3.5 & 4 & 2.8 \\
\hline & Full-time & 85 & 97.7 & 55 & 96.5 & 140 & 97.2 \\
\hline \multirow[t]{3}{*}{ Previous Statistics } & None & 8 & 9.2 & 51 & 89.5 & 59 & 41.0 \\
\hline & Intro & 26 & 29.9 & 6 & 10.5 & 32 & 22.2 \\
\hline & Further & 53 & 60.9 & 0 & 0.0 & 53 & 36.8 \\
\hline \multirow{3}{*}{$\begin{array}{l}\text { Enrolled in } \\
\text { Statistics Elective }\end{array}$} & No & 38 & 43.7 & 57 & 100.0 & 95 & 66.0 \\
\hline & Yes & 49 & 56.3 & 0 & 0.0 & 49 & 34.0 \\
\hline & & Mean & $S D$ & Mean & $S D$ & Mean & $S D$ \\
\hline Attendance(8 labs) & & 7.2 & 1.3 & 7.5 & 1.2 & 7.4 & 1.2 \\
\hline Exam \% & & 59.3 & 14.3 & 65.7 & 12.5 & 61.8 & 14.0 \\
\hline CLSI & & 4.7 & 1.2 & 4.7 & 1.1 & 4.7 & 1.2 \\
\hline
\end{tabular}

These two open-ended questions were also included in the questionnaire: 1) "Share at least one positive aspect of the computer laboratory sessions", and 2) "Was there anything that you did not like about the computer laboratory sessions or you think needs improvement? Provide details". The qualitative responses to these questions were included 
to gain insight into aspects of the sessions that impacted students' positive and negative experiences.

\section{QUANTITATIVE RESULTS}

All statistical analysis was performed using SPSS and $R$ (R Core Team, 2014). Descriptive statistics for all CLSI items were tabulated to summarise students' responses to each item (see Table 3). The mean CLSI for the sample was also included. Agreement to each item was calculated as the proportion of students who agreed, rating a particular item as 5,6 , or 7 . The percentage of students tending towards agreement (CLSI scores above 4) has also been included. Means and percentages are reported with their 95\% confidence intervals $(95 \% C I)$. The $95 \%$ CI for the proportion of agreement, converted to percentages, was based on the Wilson method as implemented in the Hmisc R package (Harrell, 2014).

Table 3. CLSI Item Statistics and Confidence Intervals $(N=144)$

\begin{tabular}{|c|c|c|c|c|c|c|}
\hline Item & Mean & $95 \% C I$ & $S D$ & Agree & $\%$ & $95 \% C I$ \\
\hline 1. Enjoyed the sessions & 4.76 & $4.49,5.03$ & 1.62 & 93 & 64.6 & $56.5,71.9$ \\
\hline $\begin{array}{l}\text { 2. Better understanding of scientific } \\
\text { research }\end{array}$ & 4.84 & $4.59,5.09$ & 1.49 & 103 & 71.5 & $63.7,78.3$ \\
\hline 3. Felt like a real quantitative researcher & 4.08 & $3.82,4.34$ & 1.56 & 62 & 43.1 & $35.3,51.2$ \\
\hline $\begin{array}{l}\text { 4. Practical experience with conducting } \\
\text { statistical analysis }\end{array}$ & 5.03 & $4.81,5.25$ & 1.32 & 108 & 75.0 & $67.3,81.4$ \\
\hline 5. Enjoyed doing statistical analysis & 4.54 & $4.27,4.81$ & 1.63 & 84 & 58.3 & $50.2,66.1$ \\
\hline $\begin{array}{l}\text { 6. Understand relationship between } \\
\text { design and analysis }\end{array}$ & 4.76 & $4.52,5.00$ & 1.44 & 96 & 66.7 & $58.6,73.8$ \\
\hline 7. Difficult to complete sessions* & 4.81 & $4.53,5.09$ & 1.71 & 33 & 77.1 & $69.6,83.2$ \\
\hline $\begin{array}{l}\text { 8. Helped improve understanding of } \\
\text { data collection }\end{array}$ & 4.72 & $4.49,4.95$ & 1.38 & 95 & 66.0 & $57.9,73.2$ \\
\hline $\begin{array}{l}\text { 9. Did not enjoy conducting statistical } \\
\text { analysis* }\end{array}$ & 4.65 & $4.35,4.95$ & 1.84 & 41 & 71.5 & $63.7,78.3$ \\
\hline $\begin{array}{l}\text { 10. Understand the role of statistical } \\
\text { analysis in research }\end{array}$ & 4.89 & $4.69,5.09$ & 1.20 & 101 & 70.1 & $62.2,77.0$ \\
\hline $\begin{array}{l}\text { 11. Felt immersed in the computer } \\
\text { sessions }\end{array}$ & 4.01 & $3.74,4.28$ & 1.62 & 55 & 38.2 & $30.7,46.3$ \\
\hline 12. Better understanding of concepts & 4.53 & $4.26,4.80$ & 1.64 & 77 & 53.5 & $45.3,61.4$ \\
\hline $\begin{array}{l}\text { 13. Gained insight into quantitative } \\
\text { research }\end{array}$ & 4.56 & $4.32,4.80$ & 1.45 & 83 & 57.6 & $49.5,65.4$ \\
\hline $\begin{array}{l}\text { 14. Increased confidence with } \\
\text { quantitative methods }\end{array}$ & 4.53 & $4.29,4.77$ & 1.48 & 84 & 58.3 & $50.2,66.1$ \\
\hline 15. Recommend to other students & 4.84 & $4.57,5.11$ & 1.63 & 94 & 65.3 & $57.2,72.6$ \\
\hline $\begin{array}{l}\text { 16. Experienced statistical issues that } \\
\text { arise during research }\end{array}$ & 4.85 & $4.61,5.09$ & 1.45 & 95 & 66.0 & $57.9,73.2$ \\
\hline $\begin{array}{l}\text { 17. Improved understanding of analysis } \\
\text { of scientific studies }\end{array}$ & 4.83 & $4.59,5.07$ & 1.44 & 98 & 68.1 & $60.1,75.1$ \\
\hline 18. Overall positive experience & 4.98 & $4.70,5.26$ & 1.70 & 101 & 70.1 & $62.2,77.0$ \\
\hline Computer Laboratory Satisfaction Index & 4.68 & $4.48,4.88$ & 1.19 & $111^{\mathrm{a}}$ & $77.1^{\mathrm{a}}$ & $69.6,83.2$ \\
\hline
\end{tabular}

${ }^{a}$ CLSI scores above 4 were considered as tending towards agreement

*Item was reverse-coded.

A series of univariate general linear models were fitted to determine whether previous statistics background, academic program, campus, tutors, or exam scores were associated with the CLSI scores. The degree to which CLSI score was dependent on these factors could be used to help understand variability in student satisfaction and lead to a better understanding of the strengths and limitations of the labs. For example, an association with 
campus or tutor might suggest the laboratory environment and tutor staff impact the student experience. Associations with previous statistics courses or exam scores highlight the importance of students' prior knowledge and academic ability. Ideally, the Island-based computer labs would share no relationship with these factors as this would mean satisfaction was robust to difference in teaching staff, lab environments, and student knowledge/ability.

For each model including a fixed factor, the assumption of homogeneity of variance was met, according to a Levene's test. For the model looking at the association between exam scores and CLSI scores, heteroscedasticity was ruled out upon visual inspection of the residual plot. The CLSI means across the levels of each factor and their corresponding $F$-tests are displayed in Table 4 . The eta-squared $\left(\eta^{2}\right)$ measure of effect size, and, where appropriate, Cohen's $d$ effect size have been reported along with CIs implemented using the MBESS $R$ package (Kelley \& Lai, 2012). The tutor factor was the only statistically significant univariate association found, accounting for $19 \%$ of the variability in the sample's CLSI scores. The campus factor had the second largest effect (Cohen's $d=0.44$, $\left.\eta^{2}=.02\right)$, and was followed closely by previous statistics $\left(\eta^{2}=.02\right)$. However, both failed to reach statistical significance, suggesting there was insufficient evidence of an association with CLSI scores. The nonsignificant and very small effect sizes for academic program and exam scores indicated that these two remaining factors were largely independent of CLSI scores.

Table 4. Five General Linear Models of CLSI Scores

\begin{tabular}{|c|c|c|c|c|c|c|c|c|c|}
\hline \multirow[t]{2}{*}{ Factor/Level } & \multirow[t]{2}{*}{ Mean } & \multirow[t]{2}{*}{$S D$} & \multirow[t]{2}{*}{$N$} & \multirow[t]{2}{*}{$F$} & \multirow[t]{2}{*}{$p$} & \multicolumn{2}{|c|}{ Cohen's $d$} & \multicolumn{2}{|c|}{$\eta^{2}$} \\
\hline & & & & & & $d$ & $95 \% \mathrm{CI}$ & $\eta^{2}$ & $95 \% \mathrm{CI}$ \\
\hline \multicolumn{10}{|l|}{ Previous Statistics } \\
\hline None & 4.69 & 1.17 & 59 & 1.72 & .18 & $\mathrm{RC}$ & & .02 & $.00, .08$ \\
\hline Intro & 4.37 & 1.17 & 32 & & & -0.27 & $-0.70,0.16$ & & \\
\hline Further & 4.86 & 1.20 & 53 & & & 0.14 & $-0.23,0.51$ & & \\
\hline \multicolumn{10}{|l|}{ Program } \\
\hline Applied psychology & 4.67 & 1.23 & 87 & 0.01 & .93 & $\mathrm{RC}$ & & .00 & $.00, .02$ \\
\hline $\begin{array}{l}\text { Social science \& } \\
\text { social work }\end{array}$ & 4.69 & 1.12 & 57 & & & 0.01 & $-0.32,0.35$ & & \\
\hline \multicolumn{10}{|l|}{ Campus } \\
\hline A & 4.23 & 1.19 & 20 & 3.43 & .07 & $\mathrm{RC}$ & & .02 & $.00, .09$ \\
\hline B & 4.75 & 1.17 & 124 & & & 0.44 & $-0.03,0.92$ & & \\
\hline \multicolumn{10}{|l|}{ Tutor } \\
\hline Tutor 1 & 3.84 & 1.14 & 33 & 8.05 & $<.01$ & $\mathrm{RC}$ & & .19 & $.07, .28$ \\
\hline Tutor 2 & 4.17 & 1.48 & 8 & & & 0.27 & $-0.50,1.05$ & & \\
\hline Tutor 3 & 4.80 & 1.11 & 39 & & & 0.85 & $0.37,1.34$ & & \\
\hline Tutor 4 & 4.97 & 1.10 & 27 & & & 1.00 & $0.46,1.54$ & & \\
\hline Tutor 5 & 5.20 & 0.89 & 37 & & & 1.34 & $0.82,1.86$ & & \\
\hline \multicolumn{10}{|c|}{ Regression slope } \\
\hline & & & & & & $b$ & $95 \%$ CI & & \\
\hline Exam & - & - & 144 & 0.42 & .52 & .01 & $-0.01,0.02$ & .00 & $.00, .04$ \\
\hline
\end{tabular}

$\mathrm{RC}$ = reference category

A general linear model with multiple explanatory variables was also explored in order to consider the multivariable effects and possible interactions between the factors. Prior to this analysis, it was important to consider the degree of multicollinearity between factors due to the large degree of association expected between some of the factors. For example, because almost all applied psychology students (90.8\%) had completed a previous statistics 
course due to their program structure, previous statistics background was expected to be highly related to the program where a student was enrolled. Table 5 presents an association matrix between the five factors under consideration. The associations reported among categorical factors and categorical and interval variables are estimates of Cramér's V and $\eta^{2}$, respectively. All measures of association are standardised effect sizes ranging from 0 to 1 . Previous stats and program were highly associated with each other, along with campus and tutor. Only one variable from each of these related pairs was carried forward into the multivariable model. To make this choice, the variable with the largest univariate effect sizes with CLSI scores was selected. This meant that previous stats, tutor, and exam variables were selected for entry into the general linear model.

Table 5. Association among Explanatory Variables

\begin{tabular}{lcccc}
\hline & \multicolumn{3}{c}{ Cramér's V } & $\eta^{2}$ \\
\hline Explanatory variable & Program & Campus & Tutor & Exam \\
\hline Previous Stats & .81 & .31 & .24 & .04 \\
Program & - & .33 & .33 & .05 \\
Campus & & - & .75 & .11 \\
Tutor & & & - & .09 \\
\hline
\end{tabular}

A general linear model using previous stats, tutor, and exam as predictors of CLSI scores was fitted. The data collected from Tutor 2 was withheld from this model as this tutor taught only students with a statistics background, which meant that their data pertaining to a possible interaction between previous stats and tutor could not be estimated. The Levene's test of homogeneity of variance was not violated and visual inspection of the model's residuals did not exhibit any further issues related to heteroscedasticity. The results of this multivariable model are reported in Table 6 and support the univariate findings. Tutor was the only statistically significant factor in the multivariable model.

Table 6. Multivariable General Linear Model of CLSI Scores $(N=136)$

\begin{tabular}{lccccc}
\hline Explanatory variable & $d f$ & $F$ & $p$ & $\eta^{2}$ & $95 \% C I$ \\
\hline Previous Statistics & 2,123 & 1.97 & .14 & .03 & $.00, .09$ \\
Tutor & 3,123 & 9.00 & $<.01$ & .18 & $.05, .26$ \\
Exam & 1,123 & 0.01 & .97 & .00 & $.00, .02$ \\
Previous Statistics by Tutor interaction & 6,123 & 0.97 & .45 & .05 & $.00, .08$ \\
\hline
\end{tabular}

Given that the factors explored in the quantitative results, besides tutor, inadequately explained student satisfaction with the Island-based labs, it was important to analyse carefully the qualitative feedback provided by the students.

\section{QUALITATIVE RESULTS}

Student qualitative feedback allowed data to be gathered that related to students' openended responses to the elements of the computer labs that they perceived as being the most positive and in need of improvement. Students' qualitative feedback gathered in the evaluation questionnaire was analysed using this six-phase thematic analysis approach described by Braun and Clark (2006): (1) familiarising yourself with the data, (2) generating initial codes, (3) searching for themes, (4) reviewing themes, (5) defining and naming themes, and (6) producing the report. Themes in the data were identified using an 
inductive, bottom-up approach. Two themes (lab design and virtual research) were identified, each containing three subthemes. Lab design related to aspects of labs that could be potentially controlled by the instructors, such as the tutors, the class environment, and time. Virtual research related to intrinsic engagement with the Island sessions, and the practicality and relevance of virtual research tasks. Each subtheme will be described alongside supporting quotations provided by participants.

\subsection{SUBTHEMES OF LAB DESIGN}

The Tutor Students reported that tutors influenced interactions with material and labs in general. Many students responded positively to clear explanations and the availability of support: “... tutor described the process of completing the tests step-by-step in a very proficient and supporting manner." However, a few felt that a single tutor was insufficient for classes that could range in size from 20-30 students: "for students left behind during the class time it may be hard for a single tutor to carry on the tute [tutorial] and help out". Additionally, feedback indicated the demeanour of tutors influenced engagement. Feedback regarding tutors was generally positive: “...the tutor is energetic, fun, exciting and connects incredibly well with students. What is otherwise a really dry subject has been made much more enjoyable by this”. However, some felt disengagement: “...relatively quiet and did not guide us well”. Both the quantitative and qualitative data highlight the importance of the tutor.

Environment The computer laboratory environment also influenced engagement during the sessions. Laboratories were reported to be fun and enjoyable for some due to the interactive nature of the sessions: “...fun to be active, having your own computer and work through the task as a group”. Students valued the clear, specific nature of the session worksheets provided: "the computer lab sheets had very clear instructions and were easy to follow”. A few students commented on the size of the lab group: “...too many people in the tute", which subsequently impacted their engagement with the Island labs. Additionally, some felt tutorials were not an appropriate environment for mixing programs (e.g., applied psychology and social science), and suggested, "segregated classes along degree lines, so students can learn in an environment conditioned to their needs".

Time Students were concerned about the activities' time-consuming nature which made them feel pressured. A key complaint concerned the speed of accessing the Island website, as several labs were simultaneously accessing the same site: "[The Island] was very slow at times and even stopped working, which made it difficult to complete the required assessments”. Many students also expressed frustration at waiting for others to finish data collection before progressing with their analysis, and the repetition of data collection. This sentiment was summarised by a student who stated, "[I] disliked how time consuming the lab activities were...took ages to actively recruit participants. When you are extremely pressured for time, it seemed a waste of time doing the lab activities every week that took majority of the tute". In contrast, some felt unable to keep up: "I felt under time pressure...but as someone who is only at an early intermediate level of research and statistics...I felt a bit overwhelmed". This suggested that students who felt rushed were students who lacked experience with statistics and statistical programs. However, this observation did not match the quantitative results, which found no association between statistics background and satisfaction. 


\subsection{SUBTHEMES OF VIRTUAL RESEARCH}

Engagement Many students considered the Island to be a useful and interesting tool for teaching research methods; however, some aspects were not valued. Specifically, some felt the Island lacked features that would make the process quicker. Some suggestions were as follows: "Should be able to ask all participants to complete a task at the same time", and "...great if there was a random suburb and participant generator built into the island..." While some enjoyed the Island's realism, a few found this frustrating, “...waiting for someone to 'smoke a reefer' for 10 minutes is such an incredible waste of my time". Overall, most students responded positively to the Island, for example, because "It provided a realistic virtual experience of ongoing research from real participants as opposed to making up data and it was interactive and almost fun at times”.

Practicality Many students were able to identify skills gained from use of the Island. Specifically, many students enjoyed experiencing the data investigative cycle, "I loved the Island, it taught me how participants are gathered, how difficult it is to get consent from everyone and it taught me the procedure of gathering and administering the experiment”. In addition, a number of students responded positively to the session for learning how to analyse data, “...inputting the data into SPSS from the results of the island is a great way to conduct SPSS tests on research you have gathered yourself”. In contrast, some felt tutorials needed to focus on interpretation and presentation of results, particularly in regards to APA style writing guidelines, rather than data collection each week, "one lab session of data entry into the island....Then the entire lab can be focused on analysing the data and presenting the results". While practical skills were gained from the Island tutorials, students felt that their data collection and SPSS skills were developed at the expense of understanding how to interpret and present results.

Relevancy Students were divided regarding the relevancy of the Island to the course. Many students understood the broader application of knowledge acquired in the lab sessions, "It reinforces the output in the lecture and allows us to put it into practice so when it comes time for assignments we have a good understanding of what to do". However, some students suggested that tutorials needed to focus specifically on course work, "...maybe too much of the tute is based around the island, a lot of waiting for others to finish when we could be going over the lecture content more. More discussion on our assignments may be good also". This view may relate to traditional expectations of tutorials and computer labs, where time is generally spent assisting with assignments.

\section{DISCUSSION}

This study reports the design, implementation, and evaluation of innovative Islandbased computer lab sessions for engaging research methods students in the data investigative cycle. These sessions aimed to improve student engagement during quantitative research methods labs designed to develop statistical thinking and problem solving (Wild \& Pfannkuch, 1999). The sessions made use of a combination of technologies, including the Island, Google Spreadsheets, and SPSS in order to virtualise quantitative research methods training. This study built upon previous work that has implemented the Island for project-based learning (Baglin, Bedford, et al., 2013; Bulmer, 2010; Linden et al., 2011) and preliminary work completed in tutorials and computer lab sessions (Baglin, Reece, et al., 2013; Linden et al., 2011). Due to poor student engagement with research methods courses (Briggs et al., 2009; Gladys et al., 2012; Meldrum \& Stults, 2012), the primary goal of this study was to evaluate students' satisfaction after implementing the sessions in a large psychology research methods course. While previous 
research completed in small classes demonstrated very high levels of student engagement (Baglin, Reece, et al., 2013; Linden et al., 2011), the level of student satisfaction reported by this study was more modest, which was not surprising, given the larger and more diverse cohort. The overall response rate to the questionnaire was $72 \%$ across both campuses, a rate which is low enough to prompt some caution; however, this proportion was considered reflective of the proportion of students who regularly attended the computer lab sessions.

Developing students' quantitative research methods skills and their broader ability to think statistically are important outcomes. Quantitative research methods courses are often the first place, in addition to the introductory statistics course, where students are exposed to the data investigative cycle; however, these courses are often viewed poorly by students, and strategies for improving engagement are often hamstrung by practical and ethical issues. Moore (1997) posited that a balanced integration of content, pedagogy, and technology will be the most likely strategy to help improve statistics education and, it is also safe to say, the quantitative research methods course. A decade later, Chance at al. (2007) reported technology as a consistent factor associated with major efforts made to improve student learning. While pedagogical practices have been greatly enhanced in the quantitative research methods course (Ball \& Pelco, 2006; Barraket, 2005; Benson \& Blackman, 2003; Crull \& Collins, 2004; Winn, 1995), this study adds to the discussion of content - namely the PPDAC cycle and statistical thinking - and provides a model of innovative technology integration that aimed to bridge the theory-practice gap with minimal practical and ethical constraints. This study is evidence that technology continues to be developed, combined, and implemented in innovative ways to support sound pedagological practice.

\subsection{TEACHING IMPLICATIONS}

When considering the factors that were associated with student satisfaction, the role of the tutor was the only statistically significant variable. Furthermore, the estimate of the tutor factor's effect size was meaningful. Tutors' CLSI ratings differed by up to 1.34 standard deviations, which equated to approximately a one-point average rating difference on the seven-point Likert-type scale. Campus had a weaker effect, but it was the second largest effect, though this may arise from the strong association of Tutor and Campus. There was insufficient evidence to conclude that satisfaction was related to whether students had previously completed a statistics course, or if they were from an applied psychology or the social science and social work program. The lack of association between exam performance and satisfaction meant that satisfaction was not a function of course performance or academic ability. A general linear model incorporating the independent factors of previous statistics background, tutor, and exam scores, further supported the main effect of the tutor's role in satisfaction. Themes from the qualitative student feedback provided valuable insight into key issues outside the factors considered by the quantitative analysis. While students saw the practical benefit of the sessions and the engaging nature of the Island simulation, many of the session mechanics impacted the student experience. Slow website response times were caused by network issues within the institution. This problem will be fixed in future iterations by mirroring the Island website on the institution's server and by network upgrades.

Many concerns with sessions related to time. Due to the ambitious goal of the sessions to simulate the entire data investigative cycle in under two hours, students were required to work diligently throughout the entire session. Students felt that time spent collecting data was wasted. While it is clear the timing of tasks within the sessions could be improved, students were unaware of the importance of gaining experience with some of the more 
mundane tasks related to research. Having students engage in active learning about vital research skills such as sampling, data collection, and data entry were largely disregarded in previous iterations of the course. The Island-based sessions provided this valuable experience and allowed students to practice it throughout the semester. Students require these skills, but the incentive to develop them during the labs may have been lost on some. Future improvements are required to convince students of the merit of these skills and later modules could gradually decrease time spent completing these tasks as students master the basics.

Students also felt there was too much included in each session; however, these concerns can be addressed with minor adjustments (e.g., by decreasing the number of samples per student). Waiting for slower students to finish their data collection also frustrated some, but simple solutions are available. For example, students could be instructed to import the class data for statistical analysis after a certain time regardless of other students' progress. Students could also be instructed on how to use their waiting time more productively, similar to what any real researcher would do. Students waiting for tasks to complete or for others to finish data collection could start drafting elements of their abstracts or outlining a data analysis plan to streamline their analysis. They could also be encouraged to find methods for cutting time and share these tips with the class. Very few students realised they could line up groups of Islanders and take them through experimental protocols by opening multiple tabs in their web browser.

The important role of the tutor was apparent both in the quantitative and qualitative findings. Tutors who were less confident with the technology and session material appeared to have negatively impacted students' perceptions. Alternatively, tutors who perhaps were more enthusiastic and knowledgeable made a positive impact. No matter how innovative and engaging the sessions may be, satisfaction will be limited without capable tutors to deliver the material. All tutors involved in the course for the study were implementing these sessions for the first time. All were trained to implement the sessions and weekly pre-lab briefing sessions with the researcher were held. The results of this study suggest that more tutor support may be needed.

\subsection{LIMITATIONS}

The applied human research focus of the Island will not apply to all student disciplines that are required to develop quantitative research and statistical thinking abilities (e.g., engineering and the physical sciences). While much of the data investigative cycle was captured in the labs, the level of detail for some important elements was guided (e.g., problem and planning) or semi-automated (e.g., sampling) due to time constraints. These element and topics require further development in later courses. For example, MacGillivary and Pereira-Mendoza (2011) advocate the use of self-selected student projects that provide students with experience in the problem and planning stages of the PPDAC cycle. The course content topics are only introductory and limited to bivariate research or simple twovariable research designs, so the sessions provide a somewhat simplified view of real (generally, multivariate) research.

The strength of the Island-based labs was the ability to engage students in the entire data investigative cycle that underpins all quantitative research methods. The sessions aimed to contextualise and integrate the various topics covered in the course in a meaningful, authentic, and practical manner. Students were given the opportunity to put theory into practice and experience the common challenges associated with research. The sessions built an understanding of how research is conducted from conceptualisation to conclusions. Many practical and ethical issues were overcome by virtualising the sessions. 
In many ways, the sessions were a substantial improvement on the previous existing labs that had students analyse pre-existing datasets; therefore, the Island-based labs acted to introduce and build fundamental quantitative research methods and statistical thinking skills in an engaging, practical, and holistic manner.

\subsection{FUTURE RESEARCH}

Further research linking completion of the Island-based labs with achievement of the course learning outcomes hypothesised to be taking place is needed. In particular, the learning synergy between the Island-based activities and other assessments that students complete during the course requires more detailed evaluation. The central learning goals of the course focus on developing three sets of skills that are considered primary learning outcomes in this area: research "thinking”, research "consuming”, and research "doing”. Assessments throughout the course are designed to foster these outcomes, and include a series of short essays on contentious methodological issues (e.g., is psychology a science?), an exercise where students are given a mock research paper and cast in the role of a journal reviewer (Cranney et al., 2011), and a more traditional data analysis exercise where students are given data to analyse and report in correctly formatted style. The question of how the Island-based activities interact with these other assessments is yet to be addressed but will be a focus of future research. Research of this type, which often requires experimental or quasi-experimental designs, often has to deal with considerable practical constraints arising from the need to manipulate how coursework is offered to groups of students.

\subsection{CONCLUSION}

In conclusion, the results of this study demonstrate how the Island, Google cloud collaboration technology, and a statistical package can be successfully used in order to simulate the entire data investigative cycle in regular, two-hour, psychology research methods computer lab sessions. Success was judged by the overall positive student attitudes towards the innovative sessions. The majority of students found the sessions engaging, of appropriate difficulty, and relevant to course learning objectives. Student satisfaction with the sessions was not found to be dependent on their discipline background (applied psychology vs. social science and social work), previous completion of a statistics course, or their overall course performance. However, the role of the tutor was highlighted as a significant factor associated with student satisfaction. Student data also provided suggestions for incremental improvements. Despite these findings, further research is needed on student satisfaction in other disciplines, and the impact of these sessions on students' attitudes towards research methods and statistics. Furthermore, in-depth evaluation is required to determine how the Island-based activities achieve course learning outcomes, how these outcomes can be reliably measured, and the degree to which students achieve these outcomes following the sessions. Ideally, the Island activities should be compared to other pedagogical methods for a meaningful comparison and to evaluate the merits of technology-based approaches.

\section{ACKNOWLEDGEMENTS}

This study was granted ethics approval by the RMIT University College Human Ethics Advisory Network on March 12, 2013. This study would not have been possible without 
the support of the course tutors and students willing to share their experience. Readers may contact the first author to request access to the Islands or to obtain copies of the worksheets.

\section{REFERENCES}

American Psychological Association (2010). Publication manual of the American Psychological Association (6th ed.). Washington, DC: Author.

Baglin, J., Bedford, A., \& Bulmer, M. (2013). Students' experiences and perceptions of using a virtual environment for project-based assessment in an online introductory statistics course. Technology Innovations in Statistics Education, 7(2), 1-15. [Online: http://www.escholarship.org/uc/item/137120mt ]

Baglin, J., Reece, J., Bulmer, M., \& Di Benedetto, M. (2013). Simulating the data investigative cycle in less than two hours: Using a virtual human population, cloud collaboration and a statistical package to engage students in a quantitative research methods course. In Proceedings of the Joint IASE/IAOS Satellite Conference. Macao, China.

[Online: http://iase-web.org/documents/papers/sat2013/IASE IAOS 2013 Paper 2.1.3 Baglin et al.pdf ]

Ball, C. T., \& Pelco, L. E. (2006). Teaching research methods to undergraduate psychology students using an active cooperative learning approach. International Journal of Teaching and Learning in Higher Education, 17(2), 147-154.

Barraket, J. (2005). Teaching research method using a student-centred approach? Critical reflections on practice. Journal of University Teaching \& Learning Practice, 2. [Online: http://ro.uow.edu.au/jutlp/vol2/iss2/3 ]

Bell, B. S., \& Kozlowski, S. W. J. (2008). Active learning: Effects of core training design elements on self-regulatory processes, learning, and adaptability. Journal of Applied Psychology, 93(2), 296-316.

Benson, A., \& Blackman, D. (2003). Can research methods ever be interesting? Active Learning in Higher Education, 4(1), 39-55.

Braun, V., \& Clarke, V. (2006). Using thematic analysis in psychology. Qualitative Research in Psychology, 3(2), 77-101.

Briggs, L. T., Brown, S. E., Gardner, R. B., \& Davidson, R. L. (2009). D.RA.MA: An extended conceptualization of student anxiety in criminal justice research methods courses. Journal of Criminal Justice Education, 20(3), 217-226.

Bulmer, M. (2010). Technologies for enhancing project assessment in large classes. In C. Reading (Ed.), Proceedings of the Eighth International Conference on Teaching Statistics. Ljubljana, Slovenia.

[Online: http://iase-web.org/documents/papers/icots8/ICOTS8 5D3 BULMER.pdf ]

Bulmer, M., \& Haladyn, J. K. (2011). Life on an Island: A simulated population to support student projects in statistics. Technology Innovations in Statistics Education, 5(1). [Online: http://escholarship.org/uc/item/2q0740hv ]

Cannon-Bowers, J., \& Bowers, C. (2010). Synthetic learning environments: On developing a science of simulation, games, and virtual worlds for training. In S. W. J. Kozlowski \& E. Salas (Eds.), Learning, training, and development in organizations (pp. 229-261). New York: Routledge.

Chance, B. L., Ben-Zvi, D., Garfield, J. B., \& Medina, E. (2007). The role of technology in improving student learning of statistics. Technology Innovations in Statistics Education, 1(1). [Online: http://escholarship.org/uc/item/8sd2t4rr ] 
Costello, A. B., \& Osborne, J. W. (2005). Best practices in exploratory factor analysis: Four recommendations for getting the most from your analysis. Practical Assessment, Research \& Evaluation, 10(7).

[Online: http://pareonline.net/pdf/v10n7.pdf ]

Cranney, J., Morris, S., Martin, F., Provost, S., Zinkiewicz, L., Reece, J., Milne-Home, J., Burton, L., White, F., Homewood, J., Earl, J., \& McCarthy, S. (2011).

Psychological literacy and applied psychology in undergraduate education. In J. Cranney \& D. Dunn (Eds.), The psychologically literate citizen: Foundations and global perspectives (pp. 146-164). New York: Oxford University Press.

Crull, S. R., \& Collins, S. M. (2004). Adapting traditions: Teaching research methods in a large class setting. Teaching Sociology, 32(2), 206-212.

Dobson, J. L. (2009). Evaluation of the virtual physiology of exercise laboratory program. Advances in Physiology Education, 33(4), 335-342.

Emmioğlu, E., \& Yesim, C. (2012). Attitudes and achievement in statistics: A metaanalysis study. Statistics Education Research Journal, 11(2), 95-102.

[Online: http://iase-web.org/documents/SERJ/SERJ11(2)_Emmioglu.pdf ]

Forster, M., \& MacGillivray, H. (2010). Student discovery projects in data analysis. In C. Reading (Ed.), Proceedings of the Eighth International Conference on Teaching Statistics. Ljubljana, Slovenia. [Online: http://iase-web.org/documents/papers/icots8/ICOTS8_4G2_FORSTER.pdf]

Galvao, J. R., Martins, P. G., \& Gomes, M. R. (2000). Modeling reality with simulation games for a cooperative learning. In J. A. Joines, R. R. Barton, K. Kang, \& P. A. Fishwick (Eds.), Proceedings of 2000 Winter Simulation Conference. Orlando, FL. doi:10.1109/WSC.2000.899158

Gladys, S., Nicholas, Z., \& Crispen, B. (2012). Undergraduate students' views on their learning of research methods and statistics (RMS) course: Challenges and alternative strategies. International Journal of Social Science Tomorrow, 1(3), 1-9.

Gould, R. (2010). Statistics and the modern student. International Statistical Review, 78(2), 297-315.

Harrell, F. E. (2014). Hmisc: Harrell Miscellaneous (R package). [Online: http://cran.r-project.org/web/packages/Hmisc/index.html ]

Holmes, P. (1997). Assessing project work by external examiners. In I. Gal \& J. B. Garfield (Eds.), The assessment challenge in statistics education (pp. 153-164). Amsterdam, The Netherlands: IOS Press.

IBM Corp. (2013). IBM SPSS Statistics for Windows, Version 22.0. Armonk, NY: IBM Corp.

Kelley, K., \& Lai, K. (2012). MBESS (R package). [Online: http://cran.r-project.org/web/packages/MBESS/index.html ]

Kolb, D. A. (1984). Experiential learning: Experience as the source of learning and development. Englewood Cliffs, NJ: Prentice-Hall.

Kolb, D. A., Boyatzis, R. E., \& Mainemelis, C. (2001). Experiential learning theory: Previous research and new directions. In R. J. Sternberg \& L. Zhang (Eds.), Perspectives on thinking, learning, and cognitive styles (pp. 227-247). Mahwah, NJ: Lawrence Erlbaum.

Lemmon, C., Lui, S. M., Cottrell, D., \& Hamilton, J. (2012). Challenges to develop an interactive 3D virtual world for psychological experiments. In Proceedings of the Sixth European Conference on Games Based Learning (pp. 278-284). [Online: http://eprints.jcu.edu.au/23255/1/23255 Lemon et al 2012.pdf ] 
Lin, X., \& Lehman, J. D. (1999). Supporting learning of variable control in a computerbased biology environment: Effects of prompting college students to reflect on their own thinking. Journal of Research in Science Teaching, 36(7), 837-858.

Linden, M., Baglin, J., \& Bedford, A. (2011). Teaching clinical trial design and management using an online virtual environment. In M. Sharma, A. Yeung, T. Jenkins, E. Johnson, G. Rayner, \& J. West (Eds.), Proceedings of the Australian Conference on Science \& Mathematics Education (17th Annual UniServe Science Conference) (pp. 107-113). Melbourne, Australia.

[Online: http://openjournals.library.usyd.edu.au/index.php/IISME/article/view/4812 ]

Longmore, M. A., Dunn, D., \& Jarboe, G. R. (1996). Learning by doing: Group projects in research methods classes. Teaching Sociology, 24(1), 84-91.

Lorenzo-Seva, U., \& Ferrando, P. J. (2006). FACTOR: A computer program to fit the exploratory factor analysis model. Behavior Research Methods, 38(1), 88-91.

MacGillivray, H., \& Pereira-Mendoza, L. (2011). Teaching statistical thinking through investigative projects. In C. Batanero, G. Burrill, \& C. Reading (Eds.), Teaching Statistics in School Mathematics-Challenges for Teaching and Teacher Education: A Joint ICM/IASE Study: The 18th ICMI Study (pp. 109-120). New York: Springer Science+Business Media B. V.

MacKay, R. J., \& Oldford, R. W. (1994). Stat 231 Course Notes Fall 1994. Waterloo: University of Waterloo.

Marriott, J., Davies, N., \& Gibson, L. (2009). Teaching, learning and assessing statistical problem solving. Journal of Statistics Education, 17(1), 1-18.

[Online: http://www.amstat.org/publications/jse/v17n1/marriott.pdf ]

Meldrum, R. C., \& Stults, B. (2012). Student performance in research methods classes: Assessing the predictive validity of the DRAMA scale. Journal of Criminal Justice Education, 23(3), 381-395.

Moore, D. S. (1997). New pedagogy and new content: The case of statistics. International Statistical Review, 65(2), 123-137.

Nelson, B. C., \& Ketelhut, D. J. (2007). Scientific inquiry in educational multi-user virtual environments. Educational Psychology Review, 19(3), 265-283.

Neumann, D. L., Neumann, M. M., \& Hood, M. (2011). Evaluating computer-based simulations, multimedia and animations that help integrate blended learning with lectures in first year statistics. Australasian Journal of Educational Technology, 27(2), 274-289.

Nevin, R. (2009). Supporting 21st century learning through Google Apps. Teacher Librarian, 37(2), 35-38.

Oswald, P. A. (1996). Classroom use of the personal computer to teach statistics. Teaching of Psychology, 23(2), 124-126.

Pfannkuch, M., \& Wild, C. (2000). Statistical thinking and statistical practice: Themes gleaned from professional statisticians. Statistical Science, 15(2), 132-152.

Pfannkuch, M., \& Wild, C. (2005). Towards an understanding of statistical thinking. In D. Ben-Zvi \& J. B. Garfield (Eds.), The challenge of developing statistical literacy, reasoning and thinking (pp. 17-46). New York: Kluwer Academic Publishers.

R Core Team (2014). R: A language and environment for statistical computing. Vienna, Austria. Retrieved from http://www.r-project.org

Ramirez, C., Schau, C., \& Emmioğlu, E. (2012). The importance of attitudes in statistics education. Statistics Education Research Journal, 11(2), 57-71.

[Online: http://iase-web.org/documents/SERJ/SERJ11(2)_Ramirez.pdf ]

Saville, B. K. (2008). A guide to teaching research methods in psychology. Malden, MA: Blackwell Publishing. 
Shapiro, A., \& Berge, J. M. F. (2002). Statistical inference of minimum rank factor analysis. Psychometrika, 67(1), 79-94.

Sizemore, O. J., \& Lewandowski, G. W. (2009). Learning might not equal liking: Research methods course changes knowledge but not attitudes. Teaching of Psychology, 36(2), 90-95.

Smith, B. (2003). Using and evaluating resampling simulations in SPSS and Excel. Teaching Sociology, 31(3), 276-287.

Snee, R. (1990). Statistical thinking and its contribution to total quality. The American Statistician, 44(2), 116-121.

Snee, R. (1993). What's missing in statistical education? The American Statistician, 47(2), 149-154.

Spinello, E. F., \& Fischbach, R. (2004). Problem-based learning in public health instruction: A pilot study of an online simulation as a problem-based learning approach. Education for Health, 17(3), 365-373.

Stafford, R., Goodenough, A. E., \& Davies, M. S. (2010). Assessing the effectiveness of a computer simulation for teaching ecological experimental design. Bioscience Education, 15(1).

[Online: http://www.bioscience.heacademy.ac.uk/journal/vol15/beej-15-1.pdf ]

ten Berge, J. M. F., \& Kiers, A. L. (1991). A numerical approach to the approximate and the exact minimum rank of a covariance matrix. Psychometrika, 56(2), 309-315.

Thomas, P. Y. (2011). Cloud computing: A potential paradigm for practising the scholarship of teaching and learning. The Electronic Library, 29(2), 214-224.

Timmerman, M. E., \& Lorenzo-Seva, U. (2011). Dimensionality assessment of ordered polytomous items with parallel analysis. Psychological Methods, 16(2), 209-220.

Wikipedia (n.d.). Cloud collaboration. Retrieved December 16, 2013 from http://en.wikipedia.org/wiki/Cloud collaboration

Wild, C., \& Pfannkuch, M. (1999). Statistical thinking in empirical enquiry. International Statistical Review, 67(3), 223-265.

Winn, S. (1995). Learning by doing: Teaching research methods through student participation in a commissioned research project. Studies in Higher Education, 20(2), 203-214.

Zablotsky, D. (2001). Why do I have to learn this if I'm not going to graduate school? Teaching research methods in a social psychology of aging course. Educational Gerontology, 27(7), 609-622.

JAMES BAGLIN

School of Mathematical and Geospatial Sciences, RMIT University

Building 251, Level 2, Room 54

PO Box 71, Plenty Rd

Bundoora VIC 3083

Australia 


\section{APPENDIX}

Table A. Factor Loadings and Communalities from the Exploratory Factor Analysis of the Island Questionnaire Rating Scales

\begin{tabular}{|c|c|c|c|}
\hline No. & Item & Loadings $^{\mathrm{a}}$ & Communality \\
\hline 1 & I enjoyed the computer laboratory sessions in this course. & .77 & .72 \\
\hline 2 & $\begin{array}{l}\text { The computer laboratory sessions gave me a better understanding } \\
\text { of scientific research design. }\end{array}$ & .68 & .79 \\
\hline 3 & $\begin{array}{l}\text { When I was in the computer laboratory sessions I felt like I was a } \\
\text { real quantitative researcher. }\end{array}$ & .64 & .66 \\
\hline 4 & $\begin{array}{l}\text { The computer laboratory sessions gave me practical experience } \\
\text { with conducting statistical analysis from scientific studies. }\end{array}$ & .73 & .68 \\
\hline 5 & $\begin{array}{l}\text { I enjoyed doing statistical analysis of scientific research in the } \\
\text { computer laboratory sessions. }\end{array}$ & .79 & .82 \\
\hline 6 & $\begin{array}{l}\text { The computer laboratory sessions helped me to understand the } \\
\text { relationship between research design and statistical analysis. }\end{array}$ & .74 & .63 \\
\hline 7 & I found it difficult to complete the computer laboratory sessions. & -.33 & .56 \\
\hline 8 & $\begin{array}{l}\text { The computer laboratory sessions helped me to improve my } \\
\text { understanding of how scientific data are collected. }\end{array}$ & .60 & .49 \\
\hline 9 & $\begin{array}{l}\text { I did not enjoy the computer laboratory sessions for conducting } \\
\text { statistical analysis. }\end{array}$ & -.61 & 66 \\
\hline 10 & $\begin{array}{l}\text { The computer laboratory sessions gave me a better understanding } \\
\text { of the role of statistical analysis in scientific research. }\end{array}$ & .69 & .68 \\
\hline 11 & I found myself immersed in the computer laboratory sessions. & .70 & .70 \\
\hline 12 & $\begin{array}{l}\text { The computer laboratory sessions helped me to better understand } \\
\text { the concepts covered in lectures. }\end{array}$ & .74 & 68 \\
\hline 13 & $\begin{array}{l}\text { The computer laboratory sessions gave me an idea of what it must } \\
\text { be like to be a quantitative researcher. }\end{array}$ & 62 & 61 \\
\hline 14 & $\begin{array}{l}\text { The computer laboratory sessions contributed to my confidence } \\
\text { in designing, conducting and analysing future scientific studies. }\end{array}$ & .75 & .65 \\
\hline 15 & $\begin{array}{l}\text { I would recommend completing the computer laboratory sessions } \\
\text { to other students who complete this course. }\end{array}$ & .82 & .75 \\
\hline 16 & $\begin{array}{l}\text { The computer laboratory sessions gave me experience in dealing } \\
\text { with statistical issues that arise during the course of scientific } \\
\text { research (e.g. selecting an appropriate statistical test, managing } \\
\text { data, missing values, etc.). }\end{array}$ & .74 & 67 \\
\hline 17 & $\begin{array}{l}\text { The computer laboratory sessions improved my understanding of } \\
\text { how scientific studies are analysed statistically. }\end{array}$ & .79 & .73 \\
\hline \multirow[t]{4}{*}{18} & $\begin{array}{l}\text { Overall, attending the computer laboratory sessions was a positive } \\
\text { experience. }\end{array}$ & .86 & .85 \\
\hline & Eigenvalue & 9.03 & \\
\hline & Total \% of Common Variance Explained & 73.4 & \\
\hline & Cronbach's $\alpha$ & .96 & \\
\hline
\end{tabular}

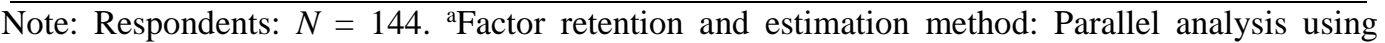
minimum rank factor analysis of the polychoric correlation matrix (Shapiro \& Berge, 2002; ten Berge \& Kiers, 1991; Timmerman \& Lorenzo-Seva, 2011). 